\title{
Dynamics of decadal variability in the Atlantic subpolar gyre: a stochastically forced oscillator
}

\author{
Andreas Born · Juliette Mignot
}

Received: 16 March 2011/Accepted: 24 August 2011/Published online: 17 September 2011

(c) Springer-Verlag 2011

\begin{abstract}
Internal variability of the Atlantic subpolar gyre is investigated in a 600 years control simulation of a comprehensive coupled climate model. The subpolar gyre shows irregular oscillations of decadal time scale with most spectral power between 15 and 20 years. Positive and negative feedback mechanisms act successively on the circulation leading to an internal oscillation. This involves periodically enhanced deep convection in the subpolar gyre center and intermittently enhanced air-sea thermal coupling. As a result, anomalies of the large-scale atmospheric circulation can be transferred to the ocean on the ocean's intrinsic time scale, exciting the oscillator stochastically. A detailed understanding of oscillatory mechanisms of the ocean and their sensitivity to atmospheric forcing holds considerable potential for decadal predictions as well as for the interpretation of proxy data records.
\end{abstract}

\section{A. Born $(\bowtie)$}

Climate and Environmental Physics, Physics Institute, University of Bern, Sidlerstrasse 5, 3012 Bern, Switzerland e-mail: born@climate.unibe.ch

\section{A. Born}

Oeschger Centre for Climate Change Research,

Bern, Switzerland

\section{A. Born}

Bjerknes Centre for Climate Research, Bergen, Norway

A. Born

Geophysical Institute, University of Bergen,

Bergen, Norway

J. Mignot

Laboratoire d'océanographie et du climat: experimentation et approches numériques, IPSL/UPMC/CNRS/IRD/MNHN, Paris, France
Keywords Ocean circulation · North Atlantic . Subpolar gyre $\cdot$ Decadal variability

\section{Introduction}

The large-scale North Atlantic ocean circulation is an important modulator of global climate, mainly because of its northward transport of heat. Changes in this transport have a wide range of consequences on various time scales ranging from the impact on ice sheets during the last glacial (Stocker 2000; Ganopolski and Rahmstorf 2001), abrupt cooling events during the early Holocene (Alley and Áugústsdóttir 2005; Wiersma et al. 2006; Born and Levermann 2010) to effects on fisheries in recent decades (Hátún et al. 2009). Many observational and modeling studies describe decadal to multidecadal variability in the Atlantic Ocean, associated with the large-scale ocean circulation and sometimes referred to as the Atlantic Multidecadal Oscillation (Delworth and Mann 2000; Kerr 2000; Dijkstra et al. 2006).

Anomalous freshwater input into the North Atlantic and adjacent Nordic Seas is considered critical for the observed variations as it may weaken the thermohaline circulation. These anomalies can typically be imposed externally onto the ocean circulation, e.g. by melting ice sheets or increased advection of sea ice, but the generation of anomalies by the circulation itself through internal variability has also been found in a number of studies (Delworth et al. 1993; Pohlmann et al. 2004; Jungclaus et al. 2005; Danabasoglu 2008; Keenlyside et al. 2008; Guemas and Salas-Melia 2008). Such a mechanism can lead to an oscillatory behavior that recently raised hope for much needed climate predictions on decadal time scale (Latif et al. 2006; Smith et al. 2007; Goddard et al. 2009). 
In this context, but also on longer time-scales, many studies identified the important role of the Atlantic subpolar gyre (SPG) (see Yoshimori et al. 2010 for an overview). This circulation system was found to redistribute freshwater anomalies in the North Atlantic and Nordic Seas (Hátún et al. 2005; Wu and Wood 2008) and to advect salinity anomalies into the Labrador Sea convection region (Delworth et al. 1993). Similar mechanisms potentially decouple the ocean circulation from atmospheric forcing and may thus develop independently (Lohmann et al.2009a, b). Idealized modeling studies showed that the gyre circulation introduces instabilities of regular occurrence that provide potential for predictions (Spall 2008).

Both observational and model studies suggest that surface wind stress has a strong influence on the SPG strength and variability (Curry et al. 1998; Böning et al. 2006). However, a number of studies emphasize the importance of the density structure on the gyre transport (Mellor et al. 1982; Greatbatch et al. 1991; Myers et al. 1996; Penduff et al. 2000; Eden and Willebrand 2001). Eden and Jung (2001) conclude that interdecadal ocean variability is primarily driven by buoyancy forcing, while the effect of variations in wind stress is limited to shorter time scales. On a more conceptual level, these characteristics of the buoyancy-driven gyre circulation were formulated as positive feedback mechanisms and their usefulness demonstrated in paleo applications (Levermann and Born 2007; Born and Levermann 2010; Born et al. 2010a, b, 2011): First, a stronger SPG transports more saline subtropical water into the subpolar North Atlantic (salt feedback). This increases the density gradient between the center and the relatively light exterior of the gyre. Sea surface elevation drops through pressure adjustments in the water column and the geostrophic response strengthens the gyre. Secondly, isopycnal mixing is intensified owing to the enhanced isopycnal outcropping associated to a stronger SPG. This results in cooling and again increases the density in the center of the SPG and therewith its strength (temperature feedback).

The original formulation of these feedback mechanisms is based on simulations with a coarse-resolution coupled climate model using in particular a simplified, statisticaldynamical atmosphere model that does not produce internal variability (Montoya et al. 2005). In this model, two SPG regimes exist that are stable over several centuries. It is the aim of the present study to further investigate these feedback mechanisms in the presence of variability simulated by a comprehensive atmosphere-ocean general circulation model. Furthermore, we will test the hypothesis that the above feedback mechanisms dynamically influence the variability.

The text is organized as follows. The coupled climate model is described in Sect. 2. Output from the model is analyzed in Sect. 3, subdivided into the presentation of SPG variability (Sect. 3.1), the analysis of driving mechanisms and feedbacks (Sects. 3.2, 3.3), and a discussion on the role of atmospheric variability (Sect. 3.4). We summarize and discuss in Sect. 4.

\section{Model description}

The simulations analyzed here have been carried out with the high-resolution version of Institut Pierre Simon Laplace coupled model version 4 (IPSL CM4), comprising ocean, sea ice, atmosphere and land surface components (Marti et al. 2010). The atmosphere is simulated by a comprehensive general circulation model (LMDZ, Hourdin et al. 2006) with a resolution of $2.5^{\circ}$ zonally by $1.875^{\circ}$ meridionally. This is higher than in the previous version used in the Coupled Model Intercomparison Project Phase 3 (CMIP3) and the Paleoclimate Modelling Intercomparison Project Phase 2 (PMIP2), that uses a lateral resolution of $3.75^{\circ}$ by $2.5^{\circ}$. The vertical grid comprises 19 levels. Precipitation over land is returned to the ocean by means of a river routing scheme implemented in the land surface model (ORCHIDEE, Krinner et al. (2005)).

The dynamical core of the ocean model is based on the OPA system (Madec et al. 1997). The configuration used here (ORCA2) uses a horizontal resolution based on a $2^{\circ}$ Mercator mesh, enhanced to $0.5^{\circ}$ meridional resolution near the equator for a better representation of the equatorial wave channel and with two poles over the continents in the Northern Hemisphere in order to avoid a singularity in the Arctic Ocean. There are 31 unevenly spaced levels in the vertical. A free-surface formulation is used for the upper boundary (Roullet and Madec 2000), allowing an explicit representation of surface freshwater fluxes instead of virtual salt fluxes. In order to reduce numerical entrainment, a diffusive boundary parametrization is used for the bottom (Madec et al. 1997; Beckmann 1998), using a coefficient of $10,000 \mathrm{~m}^{2} \mathrm{~s}^{-1}$. The eddy-induced velocity parametrization follows Gent and McWilliams (1990), using a coefficient of $2,000 \mathrm{~m}^{2} \mathrm{~s}^{-1}$.

The dynamic sea ice model (LIM2, Fichefet and Maqueda 1997; Fichefet and Maqueda 1999) uses the horizontal ocean grid to compute ice rheology and advection. Thermodynamics are computed in three vertical layers, the uppermost for snow. Ice growth and melting are determined by an energy balance at both the snow-ice and water-ice boundaries and in leads. Internal forces follow a viscous-plastic law (Hibler 1979). The model features parametrizations for the trapping of shortwave radiation by brine pockets, leads in the ice, as well as an implicit representation of subgrid variations in snow and ice thickness. 
This model has been used in its lower resolution version in several studies of past climate states (Braconnot et al. 2008; Zheng et al. 2008; Born et al. 2010b), present-day climate sensitivity to anomalous freshwater forcing (Swingedouw et al. 2007b; Mignot and Frankignoul 2009), and future projections (Swingedouw et al. 2007a; IPCC 2007). Swingedouw et al. (2007b) showed that an excess of freshwater forcing over the Labrador Sea in this model version was responsible for the lack of deep convection in this region and the relatively weak Atlantic meridional overturning circulation (AMOC) $(11 \mathrm{~Sv}=$ 11. $\left.10^{6} \mathrm{~m}^{3} \mathrm{~s}^{-1}\right)$.

The natural variability of the AMOC, its link to deep convection and its impact on the atmosphere have been studied by Msadek and Frankignoul (2009) in the low resolution version. In this version, only two deep convection regions could be defined, one in the Nordic Seas and one in the Irminger basin south of Iceland. Msadek and Frankignoul (2009) found that multidecadal fluctuations of the AMOC are mostly driven by deep convection in the subpolar gyre, which in turn is primarily influenced by the variability of the East Atlantic Pattern (EAP), the second dominant mode of atmospheric variability in the North Atlantic region. This result is probably affected by the model bias mentioned above, the lack of deep convection in the western North Atlantic and consequently an overrepresentation of the dynamics in the eastern basin (Mignot and Frankignoul 2009). The model version analyzed here, unlike the one used by Msadek and Frankignoul (2009), does show considerable variability of convection in an additional region located at the southern tip of Greenland, that is in the center of the SPG, close to the maximum of the depth-integrated volume transport (Fig. 1). This is due to an improvement of the bias described in Swingedouw et al. (2007b) (Marti et al. 2010). As shown below, this modified dynamics in the SPG has important consequences for the variability in this region.

\section{Results}

\subsection{Periodicity of the subpolar gyre}

We analyze a 600-year control run with fixed preindustrial boundary conditions. It follows a 250 -year spin-up initialized with climatological hydrography and ocean at rest. This experiment exhibits pronounced variations in the subpolar gyre index, defined as the absolute value of the local minimum of the depth-integrated streamfunction in the subpolar North Atlantic (Fig. 2). The average strength of the gyre is $21.5 \mathrm{~Sv}$ with a standard deviation of $2.0 \mathrm{~Sv}$. Most spectral power of these variations is found in the decadal band between 15 and 20 years. Periods of strong

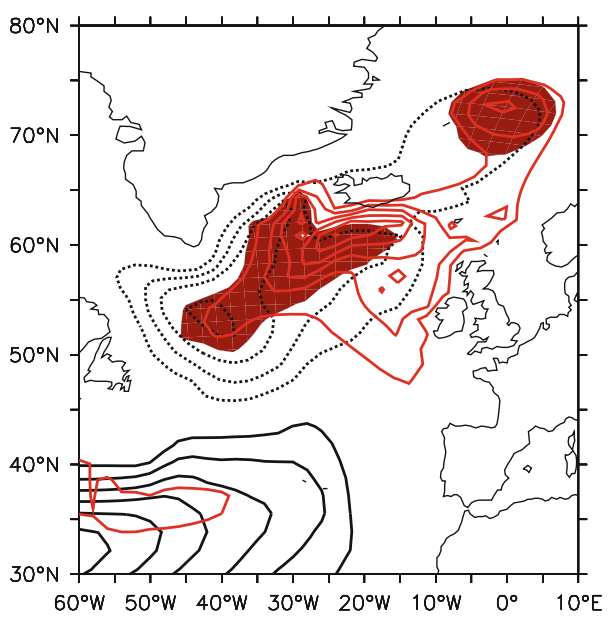

Fig. 1 Depth-integrated streamfunction, averaged over the entire duration of the experiment (black contours, spacing $5 \mathrm{~Sv}$, negative dashed), average of annual maximum mixed layer depth (red contours, spacing $300 \mathrm{~m}$ ). Red shading highlights regions where the standard deviation of the mixed layer depth exceeds $300 \mathrm{~m}$. Deep convection takes place in three regions: in the Nordic Seas, the Irminger Basin and south of Greenland (Compare with Msadek and Frankignoul (2009, Fig. 1)). The two regions south of the GreenlandScotland ridge are connected in this long-term average, but do correspond to distinct local maxima of mixed layer standard deviation

cyclonic circulation follow events of enhanced deep convection in the gyre's center, with approximately 8 years lag (Fig. 3).

Since the following analysis concerns decadal variability and is based on the characteristic time scale discussed above, all time series are filtered with a 15-year running average. This interval was chosen to remove faster variations of large amplitude but short enough to not affect the multidecadal band. Figure 3 (bottom) illustrates that the results are qualitatively unchanged for a lower frequency cut-off. This smoothing procedure reduces the degrees of freedom of the time series because in order to be independent, two signals have to be spaced at least half of the averaging interval, 7.5 years. However, the presence of decadal variations implies that signals spaced about 20 years are still correlated. Significance tests shown throughout this study thus assume a number of degrees of freedom of 600 years $/ 20$ years $=30$. We use the two-sided Student $t$ test. The significance of the frequency spectrum was tested against a set of 10,000 random realizations of red noise with autoregressive parameters estimated from the original SPG index time series.

\subsection{Vorticity balance in the North Atlantic ocean}

Unforced ocean currents follow contours of constant planetary potential vorticity, i.e. mostly topographic features and following a zonal direction where the ocean bottom is flat. Flow across these contours, for example in 
Fig. 2 Left Time series of the SPG index. Thin lines mark average value (thin solid) and standard deviations (dashed). Right Frequency spectrum of the normalized SPG index (bold solid), spectrum of fitted red noise (thin solid) with $95 \%$ confidence bounds (dashed). Most spectral power is found between 15 and 25 years

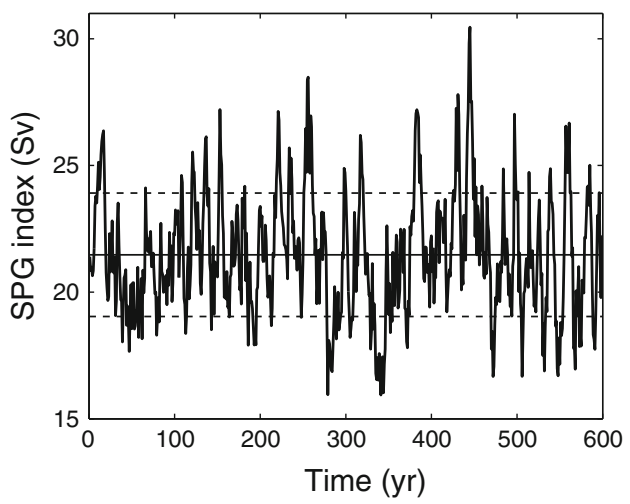

ocean gyres, requires vorticity input by one of two driving mechanisms: the curl of wind stress from the surface and baroclinicity interacting with the sloping ocean bottom from below. Following Mellor et al. (1982) and Mellor (1996), this vorticity balance is expressed mathematically as

$$
\begin{aligned}
\mathbf{M} \cdot \nabla\left(\frac{f}{H}\right)= & M_{x} \partial_{x}\left(\frac{f}{H}\right)+M_{y} \partial_{y}\left(\frac{f}{H}\right) \\
= & H^{-2}\left(\partial_{y} H \partial_{x} \Phi-\partial_{x} H \partial_{y} \Phi\right) \\
& +\partial_{x}\left(\frac{\tau_{o y}}{\rho_{0} H}\right)-\partial_{y}\left(\frac{\tau_{o x}}{\rho_{0} H}\right),
\end{aligned}
$$

where $\mathbf{M}$ is the vertically integrated volume transport vector, $f$ the Coriolis parameter, $H$ the local water depth, $\Phi=\int_{-H}^{0} d z z \cdot g\left(\rho-\rho_{0}\right) \rho^{-1}$ an expression for the potential energy, $g, \rho$ and $\rho_{0}$ the gravitational constant, local water density and reference density, and $\tau_{0 x}$ and $\tau_{0 y}$ the meridional and zonal surface wind stress. Intuitively, the dot product on the left hand side is the total integrated transport across contours of constant planetary potential vorticity, $f / H$. The first term on the right hand side is the vorticity input to the ocean due to variations in the potential energy supported by a sloping topography ('JEBAR', Sarkisyan and Ivanov 1971; Mertz and Wright 1992; Cane et al. 1998; Mellor 1999). The second term on the right hand side represents vorticity input due to wind stress.

Where bottom topography is flat, density gradients are weak or both, the first term on the right hand side of Eq. 1) becomes zero and JEBAR does not create vorticity in the ocean. In these regions, the wind stress term dominates the dynamics and Eq. 1 reduces to the topographic Sverdrup balance. However, in the presence of steep topography and strong baroclinic gradients, the JEBAR exceeds vorticity input by wind stress multiple times (Fig. 4, left). Thus, while the Sverdrup balance is a good approximation in flat parts of the tropical and subtropical North Atlantic, the SPG is driven predominantly by baroclinicity. The importance of baroclinicity for the SPG is consistent with previous work on observational data by Mellor et al.
(1982) and Greatbatch et al. (1991). Montoya et al. (2011) discuss the contribution of the respective terms of Eq. 1 to the SPG strength under different climatic boundary conditions.

Because the JEBAR scales with the invariant topographic gradient, it might be expected that the findings above apply only to the long term average, while variability is dominated by the wind forcing. Comparison of the variances of the two terms of Eq. 1 shows that the wind forcing is more variable in several regions indeed, but that the variance of the JEBAR is larger in the subpolar region (Fig. 4, right). Since the invariant topography does not contribute to the variance, this can entirely be attributed to a high variability of baroclinic fronts in this region. For the following work we will thus assume that the variability observed in the SPG index is due to baroclinic processes. A similar conclusion has been drawn from the analysis of satellite altimetry and reanalysis data (Häkkinen and Rhines 2004).

The density distribution forcing a cyclonic circulation can be estimated from the term $\partial_{x} \Phi-\partial_{y} \Phi$ of Eq. 1, setting topographic gradients equal to 1 for convenience. It becomes clear that a cyclonic circulation requires a dense core of water around which lighter water can circulate. This is equivalent to outcropping of isopycnals in the center of the SPG, that has been associated with the strength of the subpolar gyre circulation in previous studies (Häkkinen and Rhines 2004; Levermann and Born 2007; Lohmann et al. 2009b).

\subsection{Positive feedback mechanisms}

Regression of the density of the upper 1,000 $\mathrm{m}$ in the SPG center on the SPG index shows that maxima in circulation strength are associated with higher densities in the central water column (Fig. 5, left). Decomposition of the density into temperature and salinity contributions shows that higher densities are the result of a cooling of the upper $1000 \mathrm{~m}$, with salinity mostly counteracting, but below the confidence interval. Cooling is the delayed response to 

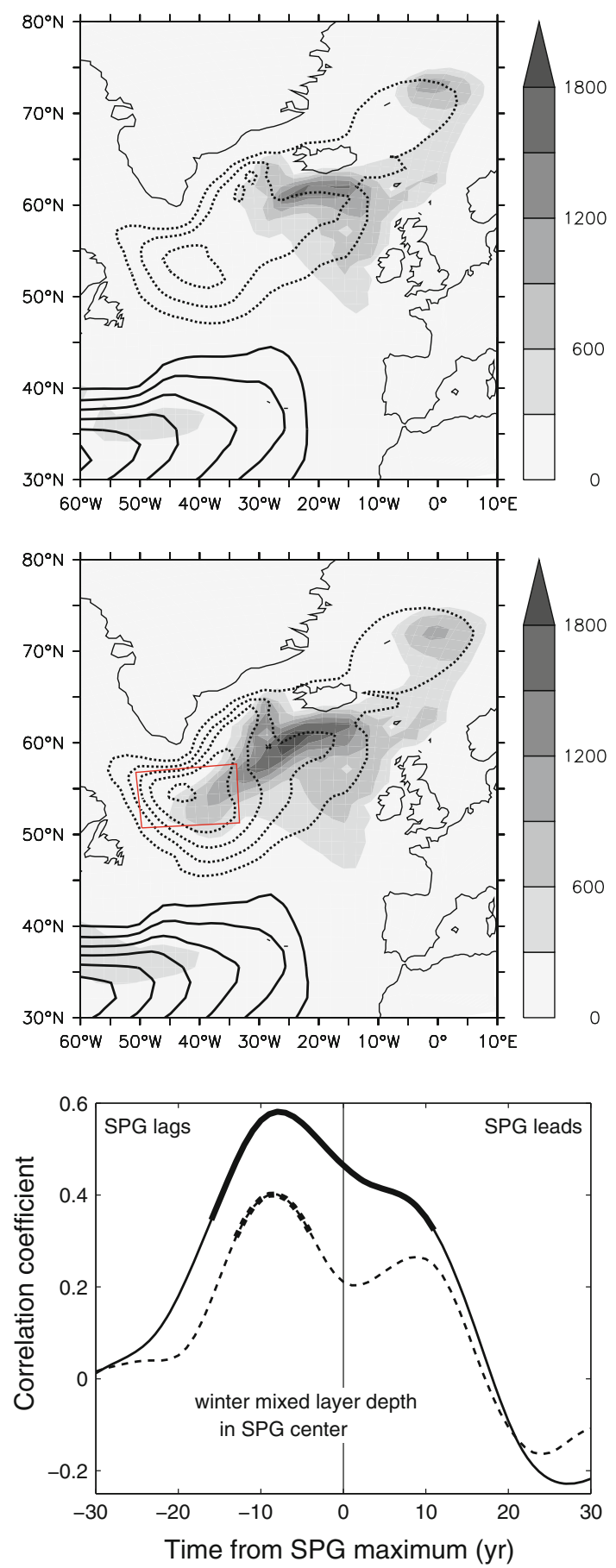

Fig. 3 Upper Composite of the depth-integrated streamfunction for the unfiltered SPG index weaker than 1.5 standard deviations (contours, spacing $5 \mathrm{~Sv}$, negative dashed) and composite mixed layer depth leading by 8 years (shading, in m). Middle As before but for SPG index stronger than 1.5 standard deviations. Red box shows SPG center region used subsequently. Lower Correlation of winter mixed layer depth in the SPG center (red box) with the normalized SPG index, 15-year (solid) and 5-year running averages (dashed). Correlations significant at the $95 \%$ level are shown as bold lines enhanced deep convection (Fig. 5, right) which occurs discontinuously in the SPG center (Fig. 3, lower). The 7 years lag between the convection maximum and the maximum cooling is owed to the thermal inertia of the water column, as confirmed by dividing the change in heat content by the rate of heat flux: $t=c_{p} \rho H T_{\text {anom }} /$ $Q_{\text {anom }}$, with $T_{\text {anom }}=-0.12{ }^{\circ} \mathrm{C} \quad \sigma_{\mathrm{SPG}}^{-1}$ and $Q_{\text {anom }}=$ $-2.12 \mathrm{~W} \mathrm{~m}^{-2} \sigma_{\mathrm{SPG}}^{-1}$ the annual average temperature of the upper $1000 \mathrm{~m}$ and upward surface heat flux anomaly as observed in the model, respectively, regressed on the SPG index and averaged over the time interval where regressions are significant. $c_{p}$ and $\rho$ are the specific heat capacity and density of water, $H$ the water depth of $1000 \mathrm{~m}$. Note that convection does not reach to a depth of $1,000 \mathrm{~m}$ continuously, but varies greatly in space, i.e. within the target region, and in time. Individual periods of enhanced convection show differences. However, the above analysis identifies the upper $1000 \mathrm{~m}$ as a reasonable estimate of the average water mass that is involved in the dynamics.

To find the cause for deep convection and destabilizing surface anomalies, the regression of the top $50 \mathrm{~m}$ density on the SPG index is analyzed. It shows a broad peak around the SPG maximum (Fig. 6). In contrast to the intermediate water column, density changes at the surface are due to salinity anomalies while contributions by temperature are not significant. Note that this logic applies only to interannual and longer variations in deep convection. Individual convective events always occur in winter as a result of strong surface heat flux. However, surface heat flux is necessary but not always sufficient to trigger convection. High surface salinities can lower the convective threshold and, due to their slow variations, allow for consecutive winters with strong convection that would not occur with winter cooling alone.

What process causes high surface salinities? Anomalous salinities due to various freshwater flux anomalies are estimated as

$\Delta S=\frac{\int^{1 \text { year }} d t F_{\text {anom }}}{A \cdot h}\left(S-S_{0}\right)$

where $F_{\text {anom }}$ is the annual anomalous volume flux, $S_{0}$ the average salinity of the target region (red box in Fig. 3) and $S$ the salinity of the volume flux. The salinity is taken as 0 in the case of air-sea exchange, 4 psu for sea ice, or as the average at the boundary of the target region in the case of lateral oceanic fluxes. Since the total lateral volume flux into the constant volume of the target region must add to zero, $\Delta S$ is calculated separately for all four of its lateral faces, whereof only the sum is presented hereafter. $A$ and $h$ are the surface area and average depth of the mixed layer, respectively, whereof the latter is defined here as the 


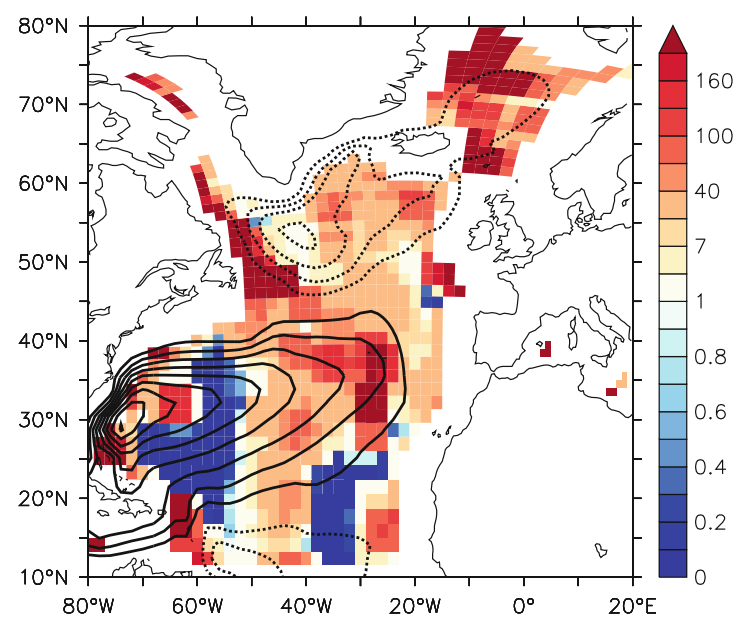

Fig. 4 Left Vorticity input into the ocean by baroclinicity in multiples of the local wind stress contribution (colors), calculated from the two right hand terms in Eq. 1 and spatially smoothed with a three-point-average. Wind stress dominates in blue regions while baroclinicity is more important in red areas. Contour lines show the time-average, depth-integrated streamfunction (spacing $5 \mathrm{~Sv}$,

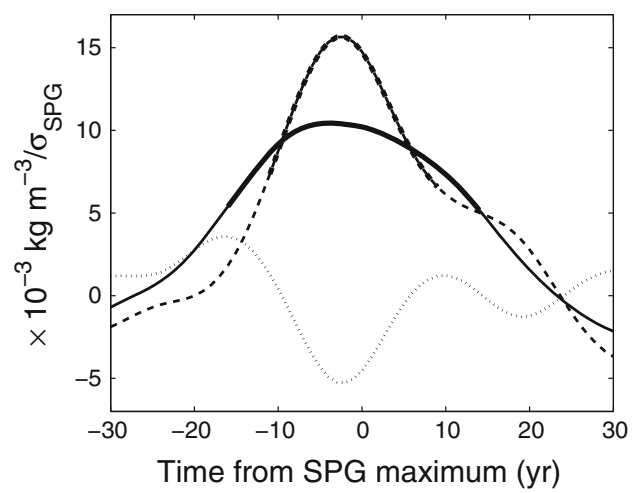

Fig. 5 Left Regression of density in the SPG center, averaged over the upper 1,000 $\mathrm{m}$, on the normalized SPG index (solid), decomposed into temperature (dashed) and salinity (dotted) contributions. Right Correlation of $1,000 \mathrm{~m}$ average temperature in the SPG center with the normalized mixed layer depth (solid). Above 95\% significance is

average over the entire 600 years experiment, $50 \mathrm{~m}$. The winter mixed layer depth in this region exceeds this value by far in some years which is potentially important for assessing the impact of surface fluxes. However, the fluxes used in this analysis are annual averages and $h$ is chosen to be consistent. Eq. 2 is based on a weighted average of the salinity of the original ocean water in the target region and the annual integral of the different anomalous fluxes. Hence, it does not strictly conserve volume which leads to a minor error estimated by the relative volume of the anomalous freshwater volume compared to the volume of the target region, less than one percent.

Anomalous salinities due to lateral advection, eddy transport, surface freshwater flux and sea ice are calculated according to Eq. 2. The impact of vertical salt transport is a

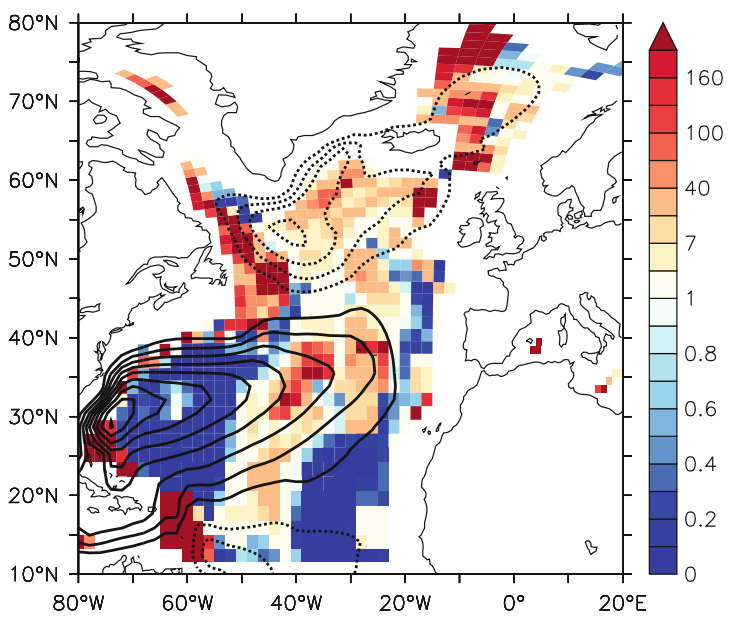

negative dashed); right as left for variance of baroclinicity and wind stress, based on unfiltered yearly data. Wind stress is the dominant source of vorticity in the ocean only in regions with flat topography. The subpolar North Atlantic has both strong topographic and baroclinic gradients, making baroclinicity the dominant source of vorticity and the more variable

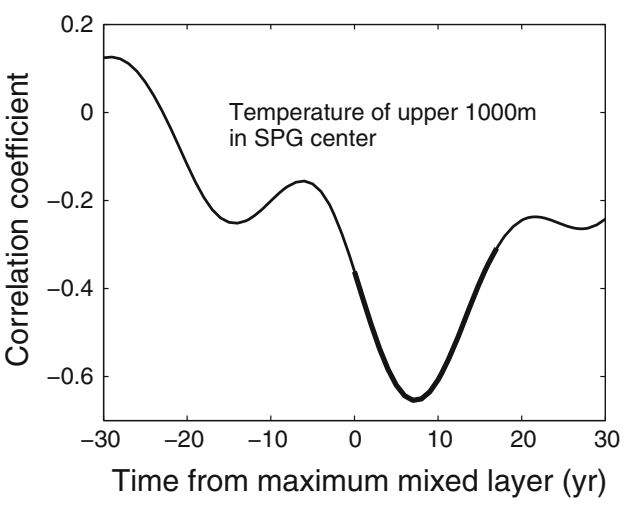

shown as bold lines. Density correlates with the SPG, mostly due to cooling of the water column. Highest densities and lowest temperatures are approximately in phase with the SPG maximum. Cooling is a response to a period of more intense deep convection with 7 years delay

complicated function of numerical parametrizations and can not be analyzed directly from the model output. It is thus taken as the residual of a salinity budget based on the above contributions and the total salinity variations simulated by the model. However, this residual is small and does not produce a significant contribution to the total salinity anomaly. Note that absolute values are not accurate because the salinity budget is not closed when calculated from annual average data.

The analysis shows two maxima for surface salinity approximately 10 years before the SPG maximum and 7 years after (Fig. 6, right). Changes in surface salinity in the SPG center are mostly due to lateral advection, including declining salinities during the 10 years prior to the SPG maximum and renewed advection into the region during the 8 years following the SPG maximum. Note that 


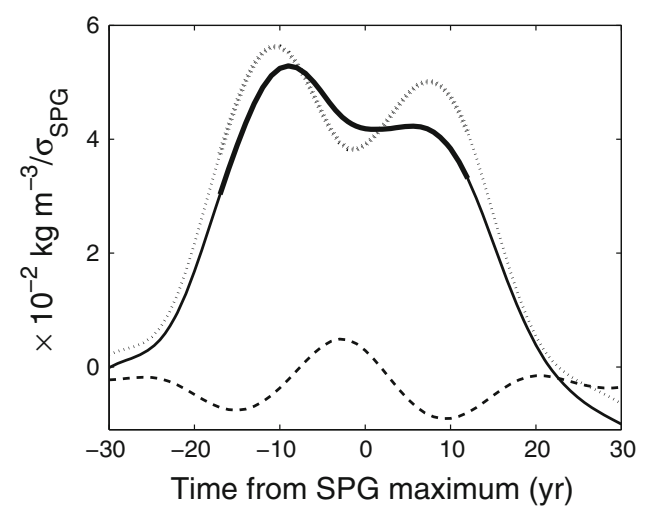

Fig. 6 Left Regression of top $50 \mathrm{~m}$ density (black solid) on the unfiltered, normalized SPG index, decomposed into temperature (black dashed) and salinity (black dotted) contributions. Right Regression of $50 \mathrm{~m}$ surface salinity (thick solid) on the unfiltered, normalized SPG index, decomposed into contributions from lateral

Fig. 6 (right) show the regression of different contributions to the salinity anomaly on the SPG index, not salt transport itself. Thus, negative slopes represent salt removal, even if the sign of the absolute signal remains positive.

The importance of salt advection to the SPG center is rather counterintuitive as the gyre circulation is usually described as flowing around an almost motionless center. Exchange with surrounding water masses is thought to be dominated by transient eddy fluxes (Spall 2004; Straneo 2006; Deshayes et al. 2009). In our model, the analysis of the spatial structure of the SPG anomalies reveals a more complex picture (Fig. 7). The cyclonic circulation anomaly at the time of the maximum SPG index allows increased transport of salt from the North Atlantic Current directly to the Greenland coast, creating a dipole in the surface salinity field (Fig. 7, upper left). This transport occurs in a northward current at approximately $35^{\circ} \mathrm{W}$, west of Reykjanes Ridge, not in the more zonally oriented Irminger Current south of Iceland. On the contrary, the Irminger Current is weaker during that part of the oscillation cycle, as seen in the anticyclonic anomaly in Fig. 7, upper left. A similar "shortcut" current has been described in float data (Fratantoni 2001; Bower et al. 2002; Orvik and Niiler 2002) and it has been observed to be non-continuous in a repeat section (Read 2001; Våge et al. 2011). In the years following the SPG maximum, the positive salinity anomaly is progressively advected westward around the southern coast of Greenland and then into the center of the SPG by the prevailing average circulation (Fig. 1, 7, upper right), partly explaining the delay in surface salinity. The cyclonic circulation anomaly moves southeastward so that anomalous streamlines connect the North Atlantic Current with the SPG center. This allows salt to be transported directly into the key region 4-8 years later (Fig. 7, lower left and right).

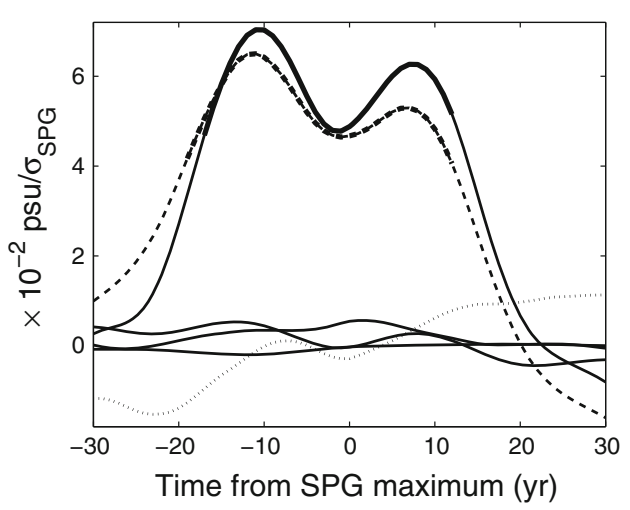

advection (dashed) and the residual salinity variation not explained by explicitly calculated contributions (dotted). Correlations significant at the $95 \%$ level are shown as bold lines. Contributions below this level are deemed negligible and shown as three thin solid lines evaporation minus precipitation, sea ice and eddy salt transport

Advection does not only build up the salinity anomaly in the SPG center, but temporarily also removes salt from the region. This occurs simultaneously with the intensification of the SPG circulation in the 10 years preceding the circulation maximum (Fig. 6, right). During this period it draws salt from the SPG center, as is still observed at the time of the maximum SPG (Fig. 7, upper left) and terminates the series of strong convective winters (Fig. 3, lower). This panel also shows that while it takes the positive salinity anomaly several years to reach the key region and enhance deep convection, the decrease in salinity is approximately in phase with the SPG strengthening. Thus, we can distinguish two effects of a stronger SPG on surface salinity, a negative immediate effect and a delayed positive one. Assuming a quasi-cyclic behavior of 17 years period, the surface salinity maximum caused by anomalously strong salt advection approximately 7-8 years after the SPG maximum is equivalent to the rise in salinity 10 years before the SPG maximum.

\subsection{Role of atmospheric variability}

Atmospheric variability plays an important role for the observed oscillations. While convection is aided by anomalously high surface salinities, individual deep convection events are always triggered by strong heat loss during winter. Particularly harsh winters can result in deep convection even with unfavorable preconditioning (Våge et al. 2009). The role of atmospheric variability in the mechanism above has thus to be clarified.

Of three possible interactions, exchanges of heat, freshwater and momentum, the direct effect of wind stress is at least one order of magnitude smaller than buoyancy forcing (Fig. 4), and therefore neglected. Of the two remaining, surface freshwater flux is found to have a 

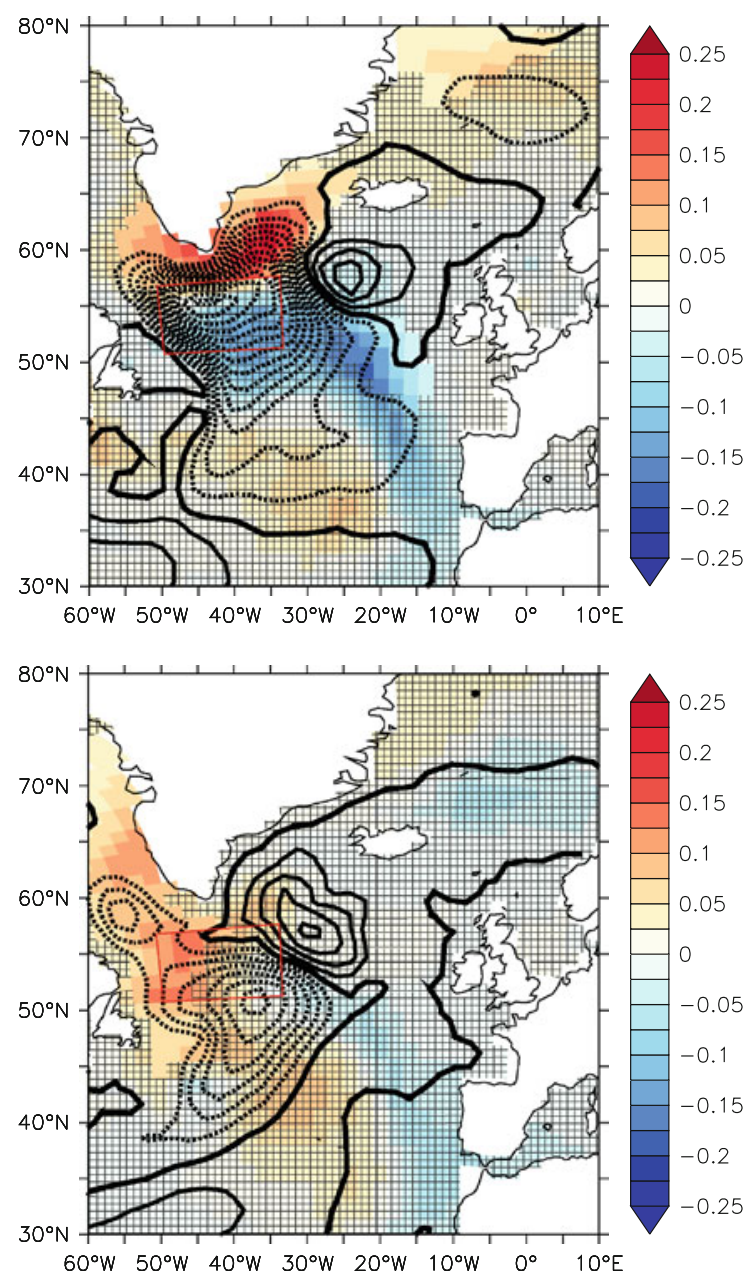

Fig. 7 Regression of $50 \mathrm{~m}$ surface salinity (colors, in psu/ $\sigma_{S P G}$ ) and depth-integrated streamfunction (contours, spacing $0.2 \mathrm{~Sv} / \sigma_{S P G}$ ) on the unfiltered, normalized SPG index, with different time lags: upper left: lag 0, upper right 2 years after maximum of SPG index, lower left 4 years after SPG, lower right 6 years after SPG. Hatching indicates areas where variations in salinity are below $95 \%$ confidence.

negligible impact on the surface freshwater balance (Fig. 6, right) and salinity anomalies in intermediate waters are insignificant (Fig. 5). Surface heat flux does not significantly change the density of water at the surface (Fig. 6, left), but contributes significantly to the cooling of the intermediate water column once surface conditions allow convection. Thus, the principal air-sea exchange is surface heat flux.

In this model, the SPG index correlates with the time series of the dominant mode of atmospheric variability in the North Atlantic, the North Atlantic Oscillation index (NAO), defined as the normalized sea surface pressure difference between Iceland and the Azores. The NAO, filtered with a 15 -year running average, leads by 5 years with $\mathrm{r}=+0.47$ ( $>95 \%$ significant). It does, however, show only weak spectral power on long time scales (Fig. 8) and is thus discarded as the direct source of the observed
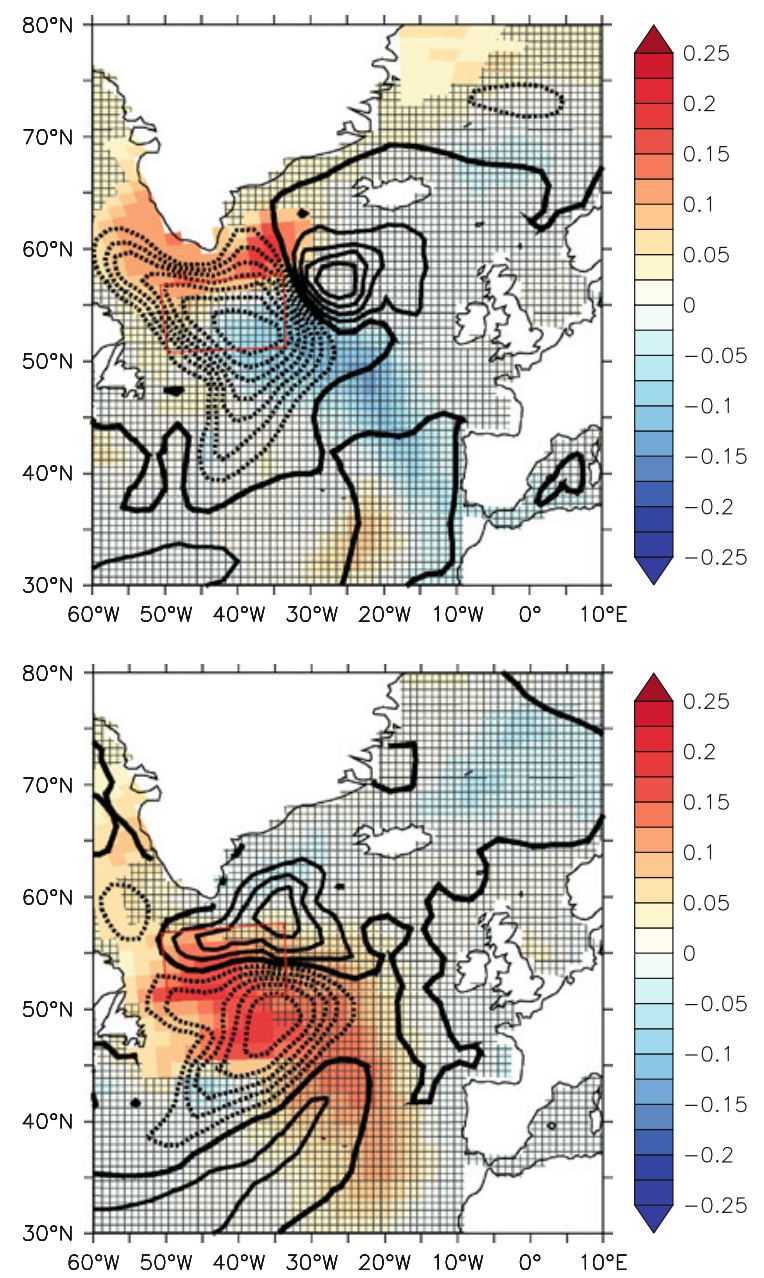

The maximum of the SPG index corresponds to a cyclonic circulation anomaly that advects saline water around the southern tip of Greenland. As time evolves, this circulation anomaly weakens and moves southeastward so that saline waters are advected into the SPG center region highlighted by the red box. This is the advective salt transport show in Fig. 6, right

decadal variability. The simple integration of high-frequency anomalous surface heat fluxes by the slowlyresponding ocean (Hasselmann 1976) does not appear sufficient to explain the variability observed here, because a surface freshwater lid periodically disconnects the sensitive water volume at depth from the influence of surface heat flux. Thus, the 17 years characteristic time scale is likely the result of oceanic processes alone.

We reconcile this apparent contradiction by interpreting the SPG as an oscillator in resonance. Due to the regular occurrence of deep convection in the SPG center, and hence stronger thermal coupling to the atmosphere, large scale atmospheric conditions influence the ocean on a characteristic time scale of approximately 17 years. The ocean filters its resonant frequency from the white noise spectrum of atmospheric forcing. During the rest of the oscillation cycle, anomalous surface freshwater is the main 


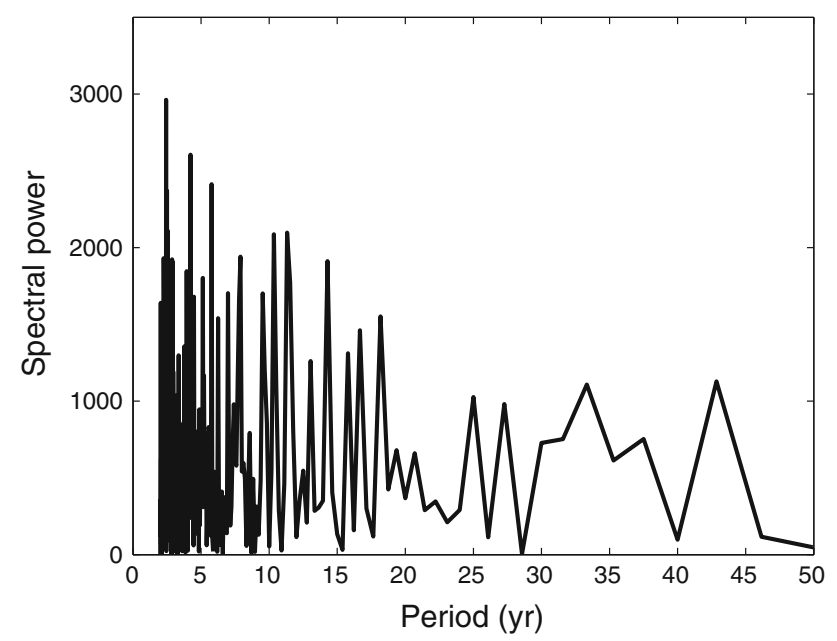

Fig. 8 Frequency spectrum of the normalized winter NAO index. Contrary to the spectrum of the SPG index, here most spectral power is found on time scales shorter than 17 years

barrier to deep convection, making it less sensitive to atmospheric heat flux anomalies. Severe winters can still break the convective barrier, but this is less likely to occur.

The notion of a convective barrier is quantified by means of the integrated buoyancy anomaly, $B_{\text {anom }}=\int_{0}^{h} \sigma d z$ $-\sigma(h) \cdot h, h=500 \mathrm{~m}$, a measure of the amount of buoyancy that must be eroded to convect to a depth of $500 \mathrm{~m}$ (Bailey et al. 2005). This quantity can be separated into temperature and salinity contributions and their difference readily identifies regions where one or the other poses the dominant barrier to deep convection (Fig. 9, upper left). The effects of a strong thermocline in the subtropics constraining convection and fresh surface waters in Arctic and Subarctic water masses are evident. It becomes clear from this analysis that deep convection in the subpolar gyre center is usually limited by freshwater. This might be exaggerated due to a model bias (Swingedouw et al. 2007b), but is qualitatively consistent with observations (Bailey et al. 2005). The freshwater lid is enhanced while the SPG is at its maximum (Fig. 9, lower left). With enhanced salt advection following a SPG maximum, this situation changes so that freshwater ceases being the dominant barrier approximately one decade later (Fig. 9, lower right). In this situation, the ocean is much more sensitive to atmospheric heat flux anomalies that occur in the same region (Fig. 9, upper right). Surface conditions change from subpolar toward more subtropical as the subpolar front, the separation of subtropical and subpolar gyres, moves northwestward (Fig. 3). As a result, periodically enhanced thermal air-sea coupling allows large-scale atmospheric conditions to influence the evolution of the SPG on one particular decadal time scale set by the ocean-a stochastically forced oscillator.

The following chain of events can thus be inferred from the above analysis (Fig. 10). A strong SPG circulation starts accumulating salt in the center of the gyre through lateral advection. This is the salt feedback of Levermann and Born (2007). Freshwater fluxes by eddies, sea ice, evaporation, precipitation and vertical salt flux are small on decadal time scales. After approximately 8 years, salinity reaches a maximum in the upper $50 \mathrm{~m}$, increasing density enough for the water column to become unstable and cause stronger deep convection with a maximum 10 years after the SPG maximum. Due to the cyclicity of the mechanism, this state 10 years after the SPG maximum is equivalent to about 10 years before the maximum. Convection causes the intermediate depth water column to start cooling through heat loss at the surface, the temperature feedback. This process takes approximately 7 years due to the large thermal inertia of the intermediate water column. Cooling results in higher densities that yield a stronger SPG. The characteristic time scale of 17 years of the quasi-oscillation is mostly owed to the two slowest processes, salt advection and cooling of the water column. While this principal chain of events works to strengthen the SPG, lateral advection also erodes the surface salinity anomaly which ultimately terminates the deep convection event. This occurs during the early phase of the SPG intensification, when advection already concentrates salt but at the expense of the SPG center region. This early response is supplanted by salt advection into the region in the decade following the SPG maximum. Advection thus both ends the present cycle through removing the surface salt anomaly and prepares the next oscillation cycle by renewed transport of salt. To sustain oscillations, it is important that salt removal is in phase with the SPG, while the renewed advection is delayed by 8 years. Atmospheric variability is conveyed to the ocean mainly through variations in surface heat flux, but only during times when ocean currents increase surface salinity sufficiently to communicate heat flux anomalies into deeper layers by convection. This forces the ocean oscillator through modulating the strength of deep convection and associated surface heat flux. However, while this leads to variations in the duration of one cycle, the characteristic time scale is determined by oceanic processes.

\section{Summary and discussion}

A combination of positive and negative feedback mechanisms has been found to destabilize the SPG, producing oscillations of irregular period in the decadal band. This allows for a revised description of feedbacks previously found in a coarse resolution model (Levermann and Born 2007). Both salt advection into the SPG center and cooling due to convection intensify with stronger circulation. However, only the temperature signal results in higher 

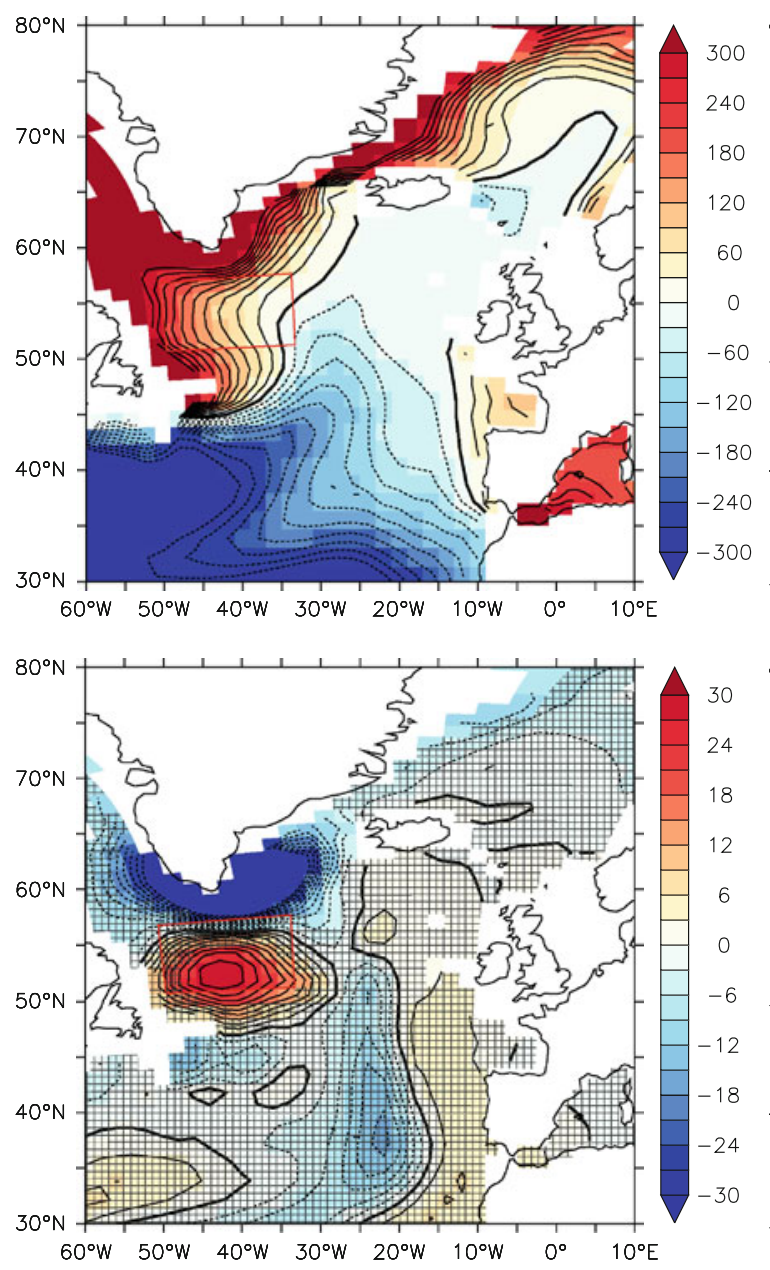

Fig. 9 Upper left Temperature minus salinity contribution of the integrated buoyancy anomaly at $500 \mathrm{~m}$, in $\mathrm{kg} \mathrm{m}^{-2}$ In regions with positive values, salinity is the dominant barrier to convection, while negative values imply that in order to allow convection a thermal barrier must be broken. Lower left Integrated buoyancy regressed onto the unfiltered, normalized SPG index at zero lag (in $\mathrm{kg} \mathrm{m}^{2} / \sigma_{S P G}$ ). Areas below the $95 \%$ confidence interval are hatched. Lower right: As before for 8 years lag after the SPG maximum. The red box

densities of the intermediate water column that in turn intensify the cyclonic circulation. Salt advection alone does not form a positive feedback loop with the SPG, because it increases the density only close to the surface. Nevertheless, it plays an important role because it thus facilitates periods of more intense convection, the prerequisite for effective cooling. In summary, intensification of the SPG circulation is the result of the interplay between (1) more intense salt advection at the surface causing stronger deep convection, and (2) the enhanced cooling of intermediate waters in response to convection which in turn strengthens the SPG and salt advection again. This view is consistent with the original description of the SPG feedbacks but combines the original two feedbacks into one, clarifying
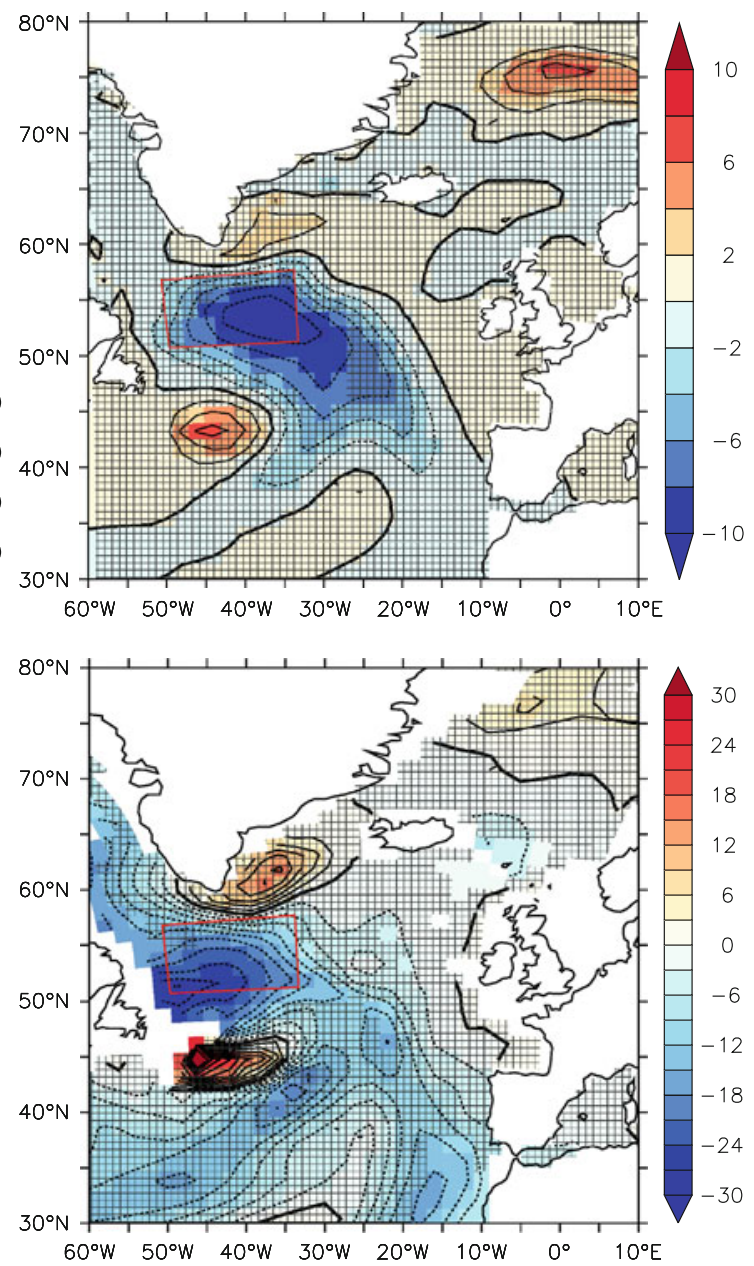

highlights the SPG center region. On average, convection is hindered by too fresh surface water in the SPG center. This tendency is amplified with the SPG index at its maximum and reduced 8 years later as a result of increased salt advection by the anomalously strong gyre in the previous decade. The region of increased sensitivity to surface heat flux is collocated with where most intense heat fluxes occur at the same time lag ( 8 years, upper right)

the respective roles of temperature and salinity anomalies for the dynamical system.

However, this mechanism does not result in a persistent intensification of the SPG because of the delays it involves. During the early intensification of the SPG, salt is also removed from its center. This occurs simultaneously with the circulation, weakens deep convection and thereby stops the cooling of the intermediate water column, effectively ending the strong phase of the SPG circulation cycle. However, the gyre remains strong for some more years due to the inertia of the cooling already achieved and continues to advect salt into the region-the beginning of the next cycle. The positive salinity anomaly thus created reaches a maximum in the key region approximately 8 years later. 


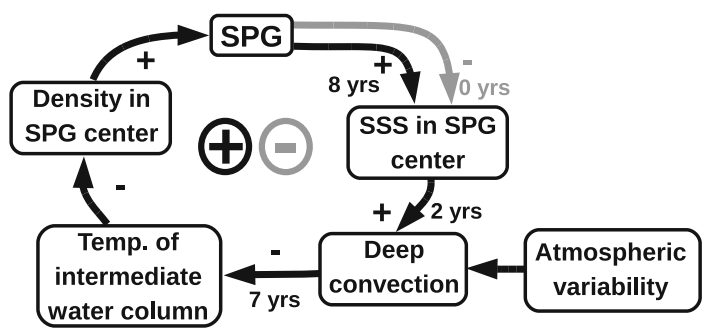

Fig. 10 Summary of the mechanisms controlling the oscillation cycle. A primary feedback loop strengthens the SPG through the advection of sea surface salinity (SSS) anomalies, deep convection and cooling of the intermediate water column. However, salt advection is delayed and the immediate result of stronger advection is the removal of salt from the key region. This causes the end of the present cycle in a secondary, negative feedback loop. Thus, advection both ends the present oscillation cycle through the removal of surface salt and initializes the next cycle by renewed positive transport with a delay. Atmospheric variability is transmitted to the ocean preferentially during times of increased convection. Thus, the ocean oscillator determines the time scale of air-sea interaction

Atmospheric variability is an important component of the observed variability and the ocean circulation follows the atmospheric low-frequency variability. Surface heat flux and cooling of the intermediate depth water column during periods of strong deep convection is the dominant air-sea coupling on decadal time scales. On the other hand, the impact of atmospheric fluxes on the upper water layers is found to be insignificant and small compared to oceanic processes. This indicates that atmospheric variability is transmitted into the deep ocean indeed and that it modulates oceanic variability, but that the time scale of interaction is determined by oceanic processes.

Two stable modes of SPG circulation were found in previous work with a coupled model that does not simulate atmospheric variability (Levermann and Born 2007). It appears a reasonable hypothesis that the presence of atmospheric variability in the more comprehensive model here causes these modes to become unstable and to induce the observed transitions, as originally proposed by Delworth et al. (1993). With our experimental set-up, however, we can not rule out that oscillations are a consequence of oceanic feedback mechanisms alone with atmospheric forcing merely modulating the duration of individual cycles. Sensitivity experiments with gradually attenuated atmospheric forcing, e.g. in an ocean-only setup, could answer this remaining question.

The rapid oscillations suggest that the dynamical system is close to a threshold in preindustrial climate where relatively weak salinity anomalies due to advection can release convection periodically, thereby influencing the intermediate depth density distribution and result in large amplitude variability of the SPG. Recent modeling work suggests that present day variability in the region can only be simulated qualitatively if the SPG is close to this dynamic threshold (Mengel et al. 2011). Changing the freshwater balance of the subpolar North Atlantic, for example by changes in Arctic sea ice export, moves the system away from the threshold, stabilizes one or the other SPG mode and thus reduces variability. This has been found in two experiments with the same climate model, albeit with lower atmospheric resolution, under different orbital configurations (Born et al. 2010b) and was found to compare favorably to climate proxy data (Born et al. 2011).

The importance of the density field for the SPG strength is well documented in observations (Mellor et al. 1982; Greatbatch et al. 1991; Mellor 1999) and numerical models (Myers et al. 1996; Penduff et al. 2000; Born et al. 2009; Montoya et al. 2011). Circulation changes of recent decades have been attributed to local buoyancy forcing (Häkkinen and Rhines 2004; Lohmann et al. 2009a). It has been shown that while changes in the wind stress field influence the SPG circulation through a barotropic response on an intraseasonal time scale, the baroclinic response to the atmosphere-ocean heat flux becomes more important on interannual time scales (Eden and Jung 2001; Eden and Willebrand 2001). Oceanic transports of heat and salt act similarly on the surface buoyancy but arguably show less variability than atmospheric surface fluxes, suggesting that the importance of oceanic transports for the SPG dynamics increases with the length of the time scale under consideration. This view is consitent with the finding that the strength of the SPG ceases to follow artificially constant NAO forcing after approximately 10 years (Lohmann et al. 2009b). A similar mechanism may also lead to damped oscillations (Eden and Greatbatch 2003). In a study of interannual to decadal variability of the North Atlantic circulation Eden and Willebrand (2001) found the enhancement of the SPG of about $2 \mathrm{~Sv} 2-3$ years after seasons of strong convection in its center, which they relate to the JEBAR. This is consistent with our findings. The shorter lag indicates a smaller volume of water involved in the convective cooling or higher surface heat fluxes or both, parameters that are likely model dependent.

Although we investigate decadal variability of the horizontal gyre circulation, the results share some similarities with findings in studies of variability in the AMOC for which advection in the SPG has repeatedly been found to play an important role (Yoshimori et al. 2010). Our work supports the interpretation of the ocean circulation oscillating in response to stochastic forcing of the atmosphere, originally proposed by Delworth et al. (1993), later confirmed by Delworth and Greatbatch (2000) and recently by Kwon and Frankignoul (2011). Variability of the SPG in IPSL CM4 does not require the existence of a coupled ocean-atmosphere mode, in contrast with some studies of AMOC variability (Weaver and Valcke 1998; 
Timmermann et al. 1998). It has been suggested that coupled ocean-atmosphere modes are related to longer time scales, superimposed on modes of faster, oceanic variability (Zhu and Jungclaus 2008). The fact that meridional advection of heat with the AMOC plays an important role in variability in several studies (Delworth et al. 1993; Timmermann et al. 1998; Zhu and Jungclaus 2008; Msadek and Frankignoul 2009; Yoshimori et al. 2010) provides a plausible explanation for this conceptual difference. Relatively long advection paths from low latitudes to the subpolar North Atlantic are responsible for the long time scales of variability, and large-scale meridional sea surface temperature gradients created by this heat transport potentially influence atmospheric dynamics. This is not the case with the local redistribution of salt in the SPG discussed here. Notwithstanding, a weak coupled mode related to the AMOC has been identified in the lower resolution version of our model (Msadek and Frankignoul 2009). With the strict definition of statistical significance and the relatively short duration of our experiment no relevant correlation was found between the SPG and the AMOC indices (not shown). This further indicates that the dynamics of the SPG are partly independent from the large scale overturning circulation. However, it should be expected, albeit unproven at this point, that since the SPG and AMOC modes of variability involve deep convection in the same region they share harmonic frequencies, as suggested by the result of Zhu and Jungclaus (2008). This suggests that detailed knowledge about the SPG dynamics holds crucial information on large-scale characteristics of the climate system.

The appreciation of advection-convection related feedbacks has led to a new understanding of the SPG in recent years, recognizing its role as an independent dynamical component of the climate system instead of following atmospheric forcing directly. By modulating Labrador Sea deep convection and thus the strength of atmosphere-ocean coupling, the dynamics of the SPG must be considered key to understanding past and future climate variability and changes. Indeed, recent analyses of marine sediments revealed that variations in SPG circulation occurred throughout the last 12,000 years, as observed both in Greenland fjords (Ren et al. 2009; Kuijpers et al. 2009), the eastern North Atlantic (Thornalley et al. 2009) and in North American slope waters (Sachs 2007).

Acknowledgments We gratefully acknowledge Sébastien Denvil for access to the model data as well as discussions with Jürgen Bader and Thomas F. Stocker. This work greatly benefited from the advice of two anonymous referees. The research leading to these results has received funding from the European Community's 7th framework program (FP7/2007-2013) under grant agreement No. GA212643 ('THOR: Thermohaline Circulation - At Risk', 2008-2012). The climate simulations were carried out in the framework of the EC-FP6 project 'ENSEMBLES'. A.B. was funded by the Marie Curie Actions project 'NICE' (MRTN-CT-2006-036127), the Research Council of Norway project 'TOPPNICE' and the National Centre of Competence in Research 'Climate' funded by the Swiss National Science Foundation. This is publication no. A367 from the Bjerknes Centre for Climate Research.

\section{References}

Alley R, Áugústsdóttir AM (2005) The 8k event: cause and consequences of a major Holocene abrupt climate change. Q Sci Rev 24:1123-1149

Bailey DA, Rhines PB, Häkkinen S (2005) Formation and pathways of North Atlantic Deep Water in a coupled ice-ocean model of the Arctic-North Atlantic Oceans. Clim Dyn 25:497-516

Beckmann A (1998) The representation of bottom boundary layer processes in numerical ocean circulation models. In: Chassignet EP, Verron $\mathrm{J}$ (eds) Ocean modeling and parametrization. pp 135-154 Kluwer Academic Publishers, Dordrecht

Böning C, Scheinert M, Dengg J, Biastoch A, Funk A (2006) Decadal variability of subpolar gyre transport and its reverberation in the North Atlantic overturning. Geophys Res Lett 33:L21S01

Born A, Kageyama M, Nisancioglu KH (2010) Warm Nordic Seas delayed glacial inception in Scandinavia. Clim Past 6:817-826

Born A, Levermann A (2010) The 8.2 ka event: abrupt transition of the subpolar gyre toward a modern North Atlantic circulation. Geochem Geophy Geosyst 11:Q06011

Born A, Levermann A, Mignot J (2009) Sensitivity of the Atlantic ocean circulation to a hydraulic overflow parameterisation in a coarse resolution model: response of the subpolar gyre. Ocean Model 27(3-4):130-142

Born A, Nisancioglu KH, Braconnot P (2010) Sea ice induced changes in ocean circulation during the Eemian. Clim Dyn 35(7): 1361

Born A, Nisancioglu KH, Risebrobakken B (2011) Late Eemian warming in the Nordic Seas as seen in proxy data and climate models. Paleoceanography (in press)

Bower A, Cann BL, Rossby T, Zenk W, Gouldk J, Speer K, Richardson P, Prater M, Zhang H-M (2002) Directly measured mid-depth circulation in the northeastern North Atlantic Ocean. Nature 419:603-607

Braconnot P, Marzin C, Grégoire L, Mosquet E, Marti O (2008) Monsoon response to changes in Earth's orbital parameters: comparisons between simulations of the Eemian and of the Holocene. Clim Past 4:281-294

Cane MA, Kamenkovich VM, Krupitsky A (1998) On the utility and disutility of JEBAR. J Phys Oceanogr 28:519-526

Curry R, McCartney M, Joyce T (1998) Oceanic transport of subpolar climate signals to mid-depth subtropical waters. Nature 391:575-577

Danabasoglu G (2008) On multidecadal variability of the atlantic meridional overturning circulation in the community climate model version 3. J Clim 21:5524-5544

Delworth T, Greatbatch RJ (2000) Multidecadal thermohaline circulation variability driven by atmospheric surface flux forcing. J Clim 13:1481-1495

Delworth TL, Manabe S, Stouffer RJ (1993) Interdecadal variations of the thermohaline circulation in a coupled ocean-atmosphere model. J Clim 6:1993-2011

Delworth TL, Mann ME (2000) Observed and simulated multidecadal variability in the Northern Hemisphere. Clim Dyn 16:661-676

Deshayes J, Straneo F, Spall MA (2009) Mechanisms of variability in a convective basin. J Mar Res 67(3):273-303 
Dijkstra HA, te Raa L, Schmeits M, Gerrits J (2006) On the physics of the Atlantic Multidecadal Oscillation. Ocean Dyn 56:36-50

Eden C, Greatbatch R (2003) A damped decadal oscillation in the north atlantic climate system. J Clim 16:4043-4060

Eden C, Jung T (2001) North Atlantic interdecadal variability: oceanic response to the North Atlantic oscillation (1865-1997). J Clim 14:676-691

Eden C, Willebrand J (2001) Mechanism of interannual to decadal variability of the North Atlantic circulation. J Clim 14:2266-2280

Fichefet T, Maqueda MAM (1997) Sensitivity of a global sea ice model to the treatment of ice thermodynamics and dynamics. J Geophys Res 102:12,609-12,646

Fichefet T, Maqueda MAM (1999) Modelling the influence of snow accumulation and snow-ice formation on the seasonal cycle of the Antarctic sea-ice cover. Clim Dyn 15:251-268

Fratantoni DM (2001) North Atlantic surface circulation during the 1990's observed with satellite-tracked drifters. J Geophys Res 106:22,067-22,093

Ganopolski A, Rahmstorf S (2001) Simulation of rapid glacial climate changes in a coupled climate model. Nature 409:153-158

Gent PR, McWilliams JC (1990) Isopycnal mixing in Ocean circulation models. J Phys Oceanogr 20:150-155

Goddard L, Baethgen W, Kirtman B, Meehl G (2009) The urgent need for improved models and predictions. EOS 90:343

Greatbatch RJ, Fanning AF, Goulding AD, Levitus S (1991) A diagnosis of interpentadal circulation changes in the North Atlantic. J Geophys Res 96:22,009-22,023

Guemas V, Salas-Melia D (2008) Simulation of the Atlantic meridional overturning circulation in an atmosphere-ocean global coupled model. Part I : a mechanism governing the variability of ocean convection in a preindustrial experiment. Clim Dyn 31:29-48

Häkkinen S, Rhines PB (2004) Decline of subpolar North Atlantic circulation during the 1990s. Science 304:555-559

Hasselmann K (1976) Stochastic climate models Part I. Theory. Tellus 28(6):473-485

Hátún H, Payne MR, Jacobsen JA (2009) The North Atlantic subpolar gyre regulates the spawning distribution of blue whiting (Micromesistius poutassou). Can J Fish Aquat Sci 66(5):759-770

Hátún H, Sandø AB, Drange H, Hansen B, Valdimarsson H (2005) Influence of the Atlantic subpolar gyre on the thermohaline circulation. Science 309:1841-1844

Hibler WD (1979) A dynamic thermodynamic sea ice model. J Phys Oceanogr 9:815-846

Hourdin F, Musat I, Bony S, Braconnot P, Codron F, Dufresne J, Fairhead L, Filiberti M, Friedlingstein P, Grandpeix J, Krinner G, Levan P, Li Z, Lott F (2006) The LMDZ4 general circulation model: climate performance and sensitivity to parametrized physics with emphasis on tropical convection. Clim Dyn 27(7$8): 787-813$

IPCC (2007) Climate change 2007: the physical science basis. Contribution of working group I to the fourth assessment report of the intergovernmental panel on climate change. In: Solomon S, Qin D, Manning M, Chen Z, Marquis M, Averyt KB, Tignor M, Miller HL (eds). Cambridge University Press, Cambridge

Jungclaus JH, Haak H, Latif M, Mikolajewicz U (2005) Arctic-North Atlantic interactions and multidecadal variability of the meridional overturning circulation. J Clim 18:4013-4031

Keenlyside N S, Latif M, Jungclaus J, Kornblueh L, Roeckner E (2008) Advancing decadal-scale climate prediction in the North Atlantic sector. Nature 453:84-88

Kerr RA (2000) A North Atlantic climate pacemaker for the centuries. Science 288:1984-1986
Krinner G, Viovy N, de Noblet-Ducoudre N, Ogee J, Polcher J, Friedlingstein P, Ciais P, Sitch S, Prentice IC (2005) A dynamic global vegetation model for studies of the coupled atmospherebiosphere system. Glob Biogeochem Cycles 19(1):GB1015

Kuijpers A, Malmgren BA, Seidenkrantz M-S (2009) Termination of the Medieval Warm Period: linking subpolar and tropical North Atlantic circulation changes to ENSO. PAGES News 17(2):76-77

Kwon Y-O, Frankignoul C (2011) Stochastically-driven multidecadal variability of the Atlantic meridional overturning circulation in CCSM3. Clim Dyn (online)

Latif M, Collins M, Pohlmann H, Keenlyside N (2006) A review of predictability studies of the Atlantic sector climate on decadal time scales. J Clim 19((23):5971-5987

Levermann A, Born A (2007) Bistability of the Atlantic subpolar gyre in a coarse-resolution model. Geophys Res Lett 34:L24605

Lohmann K, Drange H, Bentsen M (2009) A possible mechanism for the strong weakening of the North Atlantic subpolar gyre in the mid-1990s. Geophys Res Lett 36:L15602

Lohmann K, Drange H, Bentsen M (2009) Response of the North Atlantic subpolar gyre to persistent North Atlantic oscillation like forcing. Clim Dyn 32:273-285

Madec G, Delecluse P, Imbard M, Lévy C (1997) OPA version 8.1 ocean general circulation model reference manual. Institut Pierre-Simon Laplace, Note du Pôle de modélisation no 11

Marti O, Braconnot P, Dufresne J-L, Bellier J, Benshila R, Bony S, Brockmann P, Cadule P, Caubel A, Codron F, de Noblet N, Denvil S, Fairhead L, Fichefet T, Foujols M-A, Friedlingstein P, Goosse H, Grandpeix J-Y, Guilyardi E, Hourdin F, Idelkadi A, Kageyama M, Krinner G, Lévy C, Madec G, Mignot J, Musat I, Swingedouw D, Talandier C (2010) Key features of the IPSL ocean atmosphere model and its sensitivity to atmospheric resolution. Clim Dyn 34:1-26

Mellor G (1999) Comments on "on the utility and disutility of JEBAR". J Phys Oceanogr 29:2117-2118

Mellor G, Mechoso C, Keto E (1982) A diagnostic calculation of the general circulation of the Atlantic Ocean. Deep-Sea Res 29:1171-1192

Mellor GL (1996) Introduction to physical oceanography. Springer, New York

Mengel M, Levermann A, Schleussner C, Born A (2011) Enhanced subpolar-gyre variability through baroclinic threshold in the Atlantic (submitted)

Mertz G, Wright DG (1992) Interpretations of the JEBAR Term. J Phys Oceanogr 22:301-305

Mignot J, Frankignoul C (2009) Local and remote impacts of a tropical Atlantic salinity anomaly. Clim Dyn (online)

Montoya M, Born A, Levermann A (2011) Reversed north atlantic gyre dynamics in glacial climate. Clim Dyn 36(5-6):1107-1118

Montoya M, Griesel A, Levermann A, Mignot J, Hofmann M, Ganopolski A, Rahmstorf S (2005) The earth system model of intermediate complexity CLIMBER-3 $\alpha$. Part I: description and performance for present-day conditions. Clim Dyn 25:237-263

Msadek R, Frankignoul C (2009) Atlantic multidecadal oceanic variability and its influence on the atmosphere in a climate model. Clim Dyn 33:45-62

Myers PG, Fanning AF, Weaver AJ (1996) JEBAR, bottom pressure torque, and gulf stream separation. J Phys Oceanogr 26:671-683

Orvik KA, Niiler P (2002) Major pathways of Atlantic water in the northern North Atlantic and nordic seas toward Arctic. Geophys Res Lett 29:1896

Penduff T, Barnier B, de Verdière AC (2000) Self-adapting open boundaries for a sigma coordinate model of the eastern North Atlantic. J Geophys Res 105:11,279-11,298

Pohlmann H, Botzet M, Latif M, Wild M, Tschuck P (2004) Estimating the long-term predictability potential of a coupled AOGCM. J Clim 17:4463-4472 
Read J (2001) Water masses and circulation of the northeast Atlantic subpolar gyre. Prog Oceanogr 48:461-510

Ren J, Jiang H, Seidenkrantz M-S, Kuijpers A (2009) A diatom-based reconstruction of Early Holocene hydrographic and climatic change in a southwest Greenland fjord. Mar Micropaleontol $70: 166-176$

Roullet G, Madec G (2000) Salt conservation, free surface, and varying levels: a new formulation for ocean general circulation models. J Geophys Res 105:23927-23942

Sachs JP (2007) Cooling of Northwest Atlantic slope waters during the Holocene. Geophys Res Lett 34:L03609

Sarkisyan AS, Ivanov VF (1971) Joint effect of baroclinicity and bottom relief as an important factor in the dynamics of sea currents. Izvestiya Akademii Nauk SSSR Fizika Atmosfery i Okeana 7(2):173-188

Smith DM, Cusack S, Colman AW, Folland CK, Harris GR, Murphy JM (2007) Improved surface temperature prediction for the coming decade from a global circulation model. Science 317:796-799

Spall MA (2004) Boundary currents and watermass transformation in marginal seas. J Phys Oceanogr 34:1197-1213

Spall MA (2008) Low-frequency interaction between horizontal and overturning gyres in the ocean. Geophys Res Lett 35:L18614

Stocker T (2000) Past and future reorganisations in the climate system. Q Sci Rev 19:301-319

Straneo F (2006) On the connection between dense water formation, overturning, and poleward heat transport in a convective basin. J Phys Oceanogr 36:1822-1840

Swingedouw D, Braconnot P, Delecluse P, Guilyardi E, Marti O (2007) Quantifying the AMOC feedbacks during a $2 \times \mathrm{CO}_{2}$ stabilization experiment with land-ice melting. Clim Dyn 29:521-534

Swingedouw D, Braconnot P, Delecluse P, Guilyardi E, Marti O (2007) The impact of global freshwater forcing on the thermohaline circulation: adjustment of North Atlantic convection sites in a CGCM. Clim Dyn 28:291-305

Thornalley DJR, Elderfield H, McCave IN (2009) Holocene oscillations in temperature and salinity of the surface North Atlantic. Nature 457:711-714

Timmermann A, Latif M, Voss R, Grötzner A (1998) Northern hemispheric interdecadal variability: a coupled air-sea mode. J Clim 11(8):1906-1931

Våge K, Pickart RS, Sarafanov A, Knutsen Ø, Mercier H, Lherminier P, van Aken HM, Meincke J, Quadfasel D, Bacon S (2011) The irminger gyre: circulation, convection, and interannual variability. Deep Sea Res Part I: Oceanogr Res Papers 58(5):590-614

Våge K, Pickart RS, Thierry V, Reverdin G, Lee CM, Petrie B, Agnew TA, Wong A, Ribergaard MH (2009) Surprising return of deep convection to the subpolar North Atlantic Ocean in winter 2007-2008. Nat Geosci 2:67-72

Weaver AJ, Valcke S (1998) On the variability of the thermohaline circulation in the GFDL coupled model. J Clim 11(4):759-767

Wiersma AP, Renssen H, Goosse H, Fichefet T (2006) Evaluation of different freshwater forcing scenarios for the $8.2 \mathrm{ka}$ BP event in a coupled climate model. Clim Dyn 27:831-849

Wu P, Wood RA (2008) Convection induced long term freshening of the subpolar North Atlantic Ocean. Clim Dyn 31:941-956

Yoshimori M, Raible CC, Stocker TF, Renold M (2010) Simulated decadal oscillations of the Atlantic meridional overturning circulation in a cold climate state. Clim Dyn 34:101-121

Zheng W, Braconnot P, Guilyardi E, Merkel U, Yu Y (2008) ENSO at $6 \mathrm{ka}$ and $21 \mathrm{ka}$ from ocean-atmosphere coupled model simulations. Clim Dyn 30(7-8):745-762

Zhu X, Jungclaus J (2008) Interdecadal variability of the meridional overturning circulation as an ocean internal mode. Clim Dyn $31: 731-741$ 